Sharif University of Technology
Scientia Iranica
SCIENTIA

\title{
Conceptual duct shape design for horizontal-axis hydrokinetic turbines
}

\author{
A. Zahedi Nejad ${ }^{a}$, M. Rad ${ }^{b}$ and M. Khayat ${ }^{a, *}$ \\ a. Department of Mechanical and Aerospace Engineering, Science and Research Branch, Islamic Azad University, Tehran, Iran. \\ b. Department of Mechanical Engineering, Sharif University of Technology, Tehran, Iran.
}

Received 1 October 2014; received in revised form 24 August 2015; accepted 14 October 2015

\section{KEYWORDS}

Axisymmetric duct;

Conceptual design;

Eddy;

Hydrokinetic turbine;

Isothermal cavitation.

\begin{abstract}
In the present paper, conceptual duct shape design for kinetic energy extraction with hydrokinetic turbines is discussed. The goal is to find a single-passage axisymmetric geometry that holds stable flow with maximum kinetic energy flux at duct throat. For finding the optimum duct shape, the fluid flow was numerically simulated in a wedge shaped space with Flow-Simulation Software. In a multi-stage conceptual design, tabulated configurations were employed to study each geometrical characteristic separately. These include curvature of profile camber, trailing edge shape, profile tip shape, and duct exit cross sectional area. The revolved profile of each duct consists of a well constrained composite curve with few degrees of freedom. The Sketcher environment of SolidWorks Software provides a feasible method of rebuilding constrained curves. Duct shape optimization was performed based on successive flow simulation and approximation of optimum geometric dimension at optimum flow condition. The drag coefficients were compared with available experiments. Based on the numerical simulations with needle shaped leading edge, the duct throat velocity can be increased. Inversely, the flow blockage can reduce the kinetic energy flux at duct throat. The optimum duct shape has shown the greatest frictional drag coefficient and the minimum flow separation.
\end{abstract}

(C) 2016 Sharif University of Technology. All rights reserved.

\section{Introduction}

In recent years, energy extraction from river flows and tidal currents has been commercialized in many countries. Kinetic energy of water flow can be absorbed through hydrokinetic turbine. This type of turbine includes a rotor, single- or multiple-row propeller, and usually a single- or multi-pass duct for increasing power absorption. The minimum required mean flow velocity for employing hydrokinetic turbines in rivers is between $1.0 \mathrm{~m} / \mathrm{sec}$ and $1.5 \mathrm{~m} / \mathrm{sec}$ [1]. Tidal turbines have related technology to river turbines, but they extract

\footnotetext{
*. Corresponding author. Tel.: +982144868536 E-mail addresses: ali.zahedinejad@srbiau.ac.ir (A. Zahedi Nejad); rad@sharif.edu (M.Rad); mkhayat@srbiau.ac.ir (M. Khayat)
}

energy from sea or ocean currents. In the early 1990s, various types of tidal and river turbines were built. UEK Company in United States constructed a freestream water turbine with a float diffuser, named underwater electric kite [2]. Then, United Kingdom tested a tidal turbine in the renewable energy center located in Blyth [2]. In 2005, Hammerfest-Storm Company constructed a Norwegian design [2]. Innovative designs in the United States and United Kingdom have led to construction of small hydro-turbines with names Stingray and Sea-Snail and gained significant public attention. Most innovative designs for small turbines were patent technologies meant for large-scale tidal energy conversion. Design and performance data of these designs that can be used as river turbines are not available in the public domain. Two important numerical methods in analysis of hydrokinetic 
turbines are vortex lattice methods and free-vortex wake methods. With growth of computation power in the 1970s, vortex lattice models were developed and employed for analyzing Darrieus-type turbines. Vortex lattice models are based on potential flow theory while the effects of fluid viscosity are usually inserted as modifications. In 1979, Strikland presented one of the three-dimensional models for flow analysis based on vortex lattice model. He could model airfoil stall by combining the Kutta-Joukowski law and experimental data of airfoil sections [3]. Many numerical modeling techniques such as disk-stream tube and vortex panel methods have limitations in predicting transient performance of hydrokinetic turbines. According to the literature, implementation of modern CFD methods for three-dimensional modeling of transient fluid flow around ducted hydrokinetic turbine has gained great attention. Computational fluid dynamics modeling coupled with single-degree-of-freedom motion of rotor is a perfect solution for predicting performance of hydrokinetic turbines [4]. The maximum energy that a single-stage axial turbine can absorb from fluid is widely accepted in the turbine industry and is known as Lanchester-Betz limit [5]. In 2003, Kirke compared performances of ducted and unducted hydrokinetic turbines. He experimentally studied the effect of duct on increasing flow velocity through duct and named it diffuser-augmented turbine [6]. In 2003, Lawn studied performance of axial flow ducted turbine analytically using a one-dimensional theory [7]. Based on the results of Lawn, with a diffuser-augmented hydrokinetic turbine, the power coefficient can increase over $30 \%$ when compared to unducted turbines [8]. In 2004, Setuguchi et al. tried for designing and manufacturing a duct with two passages [9]. They found that a key factor for increasing the efficiency of the duct is its shape. In 2004, in United Kingdom, Bryden et al. developed a one-dimensional open-channel model. They investigated maximum attainable energy by an axial hydrokinetic turbine. Based on their findings, the maximum extractable energy was $10 \%$ of undisturbed flow kinetic energy [10,11]. In 2005, Garrett et al. studied maximum attainable energy by a fence of axial hydrokinetic turbines $[12,13]$. They presented an equation to predict the maximum power of the fence of turbines based on developed pressure gradient. In 2009, Munch et al. numerically investigated a fourblade ducted tidal turbine. They numerically simulated transient turbulent flow in ANSYS CFX Software. They showed that with tip speed ratio of seven, the turbine power coefficient exceeds 55\% [14]. In 2010, Crawford and Shives numerically simulated overall efficiency of a ducted tidal turbine using ANSYS CFX Software [15]. They showed that the power coefficient of a turbine can increase while the turbine efficiency is reduced due to induced drag force. In 2012, Shives and
Crawford presented an empirical model and validated the Lawn model by repeating calculations [16]. In the present paper, the method of conceptual duct shape design for a hydrokinetic turbine is presented.

\section{Governing equations}

For modeling unsteady turbulent flow with isothermal cavitation model, the Favre-averaged Navier-Stockes equations are solved within the Flow-Simulation Software [17]. The governing equations are [18]:

- Continuity equation of the mixture: Employing indicial notation in Cartesian coordinate system, the continuity equation is written as:

$$
\frac{\partial \rho_{m}}{\partial t}+\frac{\partial\left(\rho_{m} u_{i}\right)}{\partial x_{i}}=0
$$

- Momentum equation of the mixture phase: The fluid was considered to be Newtonian. The indicial notation for momentum equations in Cartesian coordinate system is expressed as:

$$
\begin{aligned}
\frac{\partial\left(\rho_{m} u_{i}\right)}{\partial t} & +\frac{\partial\left(\rho_{m} u_{i} u_{j}\right)}{\partial x_{j}}=-\frac{\partial p}{\partial x_{i}} \\
& +\frac{\partial}{\partial x_{j}}\left[\mu_{m}\left(\frac{\partial u_{i}}{\partial x_{j}}+\frac{\partial u_{j}}{\partial x_{i}}-\frac{2}{3} \delta_{i j} \frac{\partial u_{i}}{\partial x_{i}}\right)\right] \\
& +\frac{\partial}{\partial x_{j}}\left(-\rho_{m} \overline{u_{i}^{\prime} u_{j}^{\prime}}\right) .
\end{aligned}
$$

- Turbulence equations: Flow-Simulation Software as an integrated part of SolidWorks Software employs one system of equations to describe both laminar and turbulent flows. To predict turbulent flow, the Favre-averaged Navier-Stokes equations are solved, where time-averaged effects of the flow turbulence on the flow parameters are considered [18]. Transport equations for turbulent kinetic energy and dissipation rate are solved in FlowSimulation Software. The $\kappa-\varepsilon$ turbulence model has reasonable accuracy in boundary layer flows subjected to inverse pressure gradients. Ignoring buoyancy force, the $\kappa-\varepsilon$ transport equations for $\kappa$ and $\varepsilon$ are Eqs. (3) and (4), respectively.

$$
\begin{aligned}
& \frac{\partial\left(\rho_{m} \kappa\right)}{\partial t}+\frac{\partial\left(\rho_{m} u_{i} \kappa\right)}{\partial x_{i}}=\frac{\partial}{\partial x_{i}}\left[\left(\mu_{m}+\frac{\mu_{t}}{\sigma_{\kappa}}\right) \frac{\partial \kappa}{\partial x_{i}}\right]+S_{\kappa}, \\
& \frac{\partial\left(\rho_{m} \varepsilon\right)}{\partial t}+\frac{\partial\left(\rho_{m} u_{i} \varepsilon\right)}{\partial x_{i}}=\frac{\partial}{\partial x_{i}}\left[\left(\mu_{m}+\frac{\mu_{t}}{\sigma_{\varepsilon}}\right) \frac{\partial \varepsilon}{\partial x_{i}}\right]+S_{\varepsilon} .
\end{aligned}
$$

Based on the Modified Wall Function approach, a laminar-turbulent boundary layer model is used to describe the flow near wall regions. This model 
uses the Van Driest profile to characterize laminar and turbulent flows near the walls and describe the transition from laminar to turbulent flow and vice versa. If the size of the mesh cell near the wall exceeds the boundary layer thickness, the integral boundary layer approach is activated. This model provides accurate boundary condition for conservation equations.

- Energy equation and the equation of state: The flow over duct is low-velocity. With implementation of isothermal cavitation model, the energy equation is not solved. Referring to thermodynamic tables, the saturation pressure for water at the temperature of $20^{\circ} \mathrm{C}$ is $2339 \mathrm{~Pa}$. The liquid phase is considered as an incompressible fluid. The fluid density is defined by the barotropic equation of state. The non-condensable gas is air and the mass fraction is $10^{-4}$. The ideal gas law is employed for gaseous phase density, including vapor and noncondensable gas.

- Equilibrium mass transfer: The mass transfer in the fluid flow is governed by species conservation equations. The equations that describe mass concentration of mixture components are expressed as:

$$
\frac{\partial\left(\rho_{m} y_{n}\right)}{\partial t}+\frac{\partial\left(\rho_{m} u_{i} y_{n}\right)}{\partial x_{i}}=S_{n}
$$

$S_{n}$ is the rate of production or consumption of the $n$th component of the mixture and $y_{n}$ is the species concentration of the $n$th mixture component. According to Eq. (6), the mass fraction of vapor phase is computed numerically from a non-linear equation for the full-enthalpy gas-liquid mixture:

$$
\begin{aligned}
H= & y_{g} h_{g}(T, P)+\left(1-y_{g}-y_{v}\right) h_{l}(T, P) \\
& +y_{v} h_{v}(T, P)+\frac{I_{C} v^{2}}{2}+\frac{5}{2} \kappa .
\end{aligned}
$$

In Eq. (6), $H$ is the full enthalpy of the mixture; $T$ is a function of pressure; and $h_{g}, h_{l}$, and $h_{v}$ are the enthalpies of non-condensable gas, liquid, and vapor, respectively; also, $I_{C}=\left(\rho u_{x}\right)^{2}+\left(\rho u_{y}\right)^{2}+\left(\rho u_{z}\right)^{2}$ is the square impulse.

\section{The problem setup}

\subsection{Geometry}

The technique presented in this paper prescribes how to employ a wedge shaped fluid sub-domain in the Flow-Simulation Software for external flow modeling. As shown in Figure 1, the computational domain was a rectangle with $12.0 \mathrm{~m}$ length in positive $x$ direction, $4.0 \mathrm{~m}$ height in positive $z$-direction, and $0.55 \mathrm{~m}$ width in negative $y$-direction. Fluid sub-domain

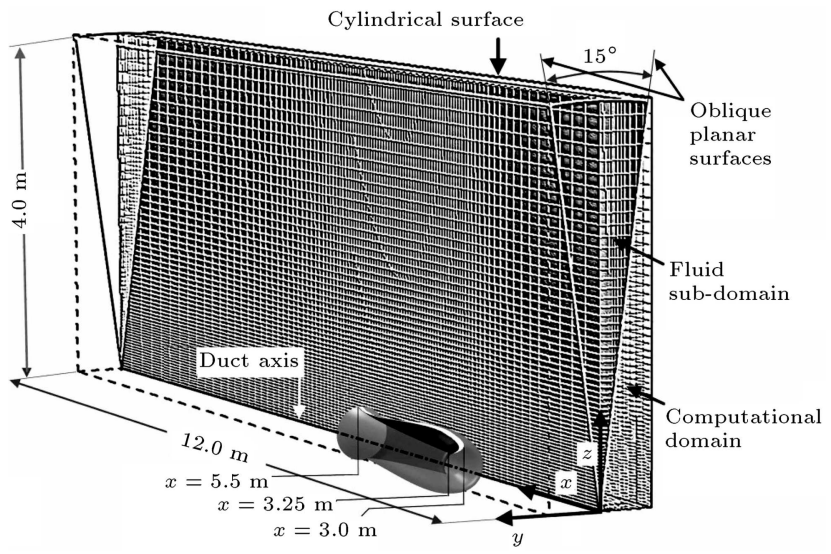

(a)

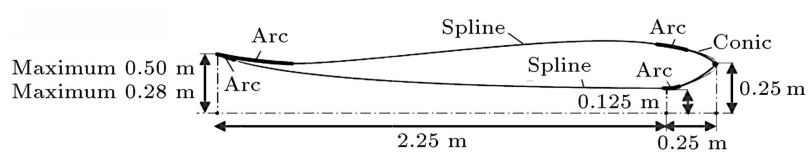

(b)

Figure 1. (a) Computational domain, fluid sub-domain, and duct geometry in a wedge shaped space. (b) definition of duct profile with a composite curve.

is completely enclosed by computational domain. Fluid sub-domain is a section of 3-D space, separated by two oblique planar surfaces passing through duct axis, and constructs a wedge shape with 15-degree angle. The outer surface of the wedge shaped fluid sub-domain is a cylindrical surface. Half of the fluid sub-domain is located inside the computational mesh. The axis of wedge shaped fluid sub-domain is along the $x$-axis, staring from origin and terminating at $x=12.0 \mathrm{~m}$. Duct leading edge is located at $x=3.0 \mathrm{~m}$ and duct throat is located at $x=3.25 \mathrm{~m}$ such that the length of converged section is $0.25 \mathrm{~m}$. The duct trailing edge is located at $x=5.50 \mathrm{~m}$ and the length of diverged section is $2.25 \mathrm{~m}$. The duct inlet diameter is $0.50 \mathrm{~m}$ and the duct throat diameter is $0.25 \mathrm{~m}$. Length of all models is $2.50 \mathrm{~m}$, except for Model 3-C that has a length of $1.65 \mathrm{~m}$ while its trailing edge is located at $x=4.65 \mathrm{~m}$. The duct profile consists of a composite curve with connected circular arcs, conic, and splines. Each two connected curves are continuous in slope and curvature. The sketch of duct profile is drawn in the Sketcher environment of SolidWorks Software as the base of the revolved duct section. The Sketcher environment of SolidWorks Software provides a feasible method of rebuilding constrained curves while a sketch is drawn based on formula and geometric constraints.

\subsection{Meshing technique}

Cartesian mesh was employed for all numerical simulations of the fluid flow around various duct shapes. The Cartesian mesh is rapidly updated as the duct shape is rebuilt. The Grid stretching technique was employed to reduce the number of computational cells. The greatest 
grid stretching ratio was less than five. To capture the fluid-solid interface, partial cells on the wall boundaries were split uniformly to control the maximum angle between the cell surface normal vectors. The fluid subdomain consisted of 60,000 computational cells with approximately 40,000 partial cells.

\subsection{Boundary conditions}

A pressure boundary that describes zero gradients of flow variable at external boundaries is named environmental pressure boundary condition. This boundary type is suitable for external flow modeling. Environmental pressure boundary well describes free stream flow and the wake flow. The minimum velocity of water current required according to the literature is typically between $1.03 \mathrm{~m} / \mathrm{sec}$ and $2.06 \mathrm{~m} / \mathrm{sec}$ [19]. Optimum currents are in the range of $2.57 \mathrm{~m} / \mathrm{sec}$ to $3.6 \mathrm{~m} / \mathrm{sec}$ [19]. In the present paper, the value of $3 \mathrm{~m} / \mathrm{s}$ was considered for optimum currents in river and tidal flows. In all cases, the free-stream pressure was $1 \mathrm{~atm}$ and the free-stream temperature was $20^{\circ} \mathrm{C}$. The free-stream turbulent intensity was $5 \%$. The cavitation number was high enough that the local mixture density remained nearly constant. To simplify the problem of designing an axisymmetric geometry, the gravitational acceleration that held hydrostatic pressure in water was neglected. The shape design was performed for ducts with smooth walls and the no-slip boundary condition was used in the numerical simulations. Idealwall boundary conditions were used for oblique planar surfaces of the fluid sub-domain. Ideal wall corresponds to the well-known slip condition and can be used as flow symmetry-plane [18].

\section{Numerical solution technique}

The numerical solution technique employed in FlowSimulation Software is robust and reliable. It solves the governing equations with the finite volume method on a spatially rectangular computational mesh. The governing equations are discretized in a conservative form. The spatial derivatives are approximated with an implicit first-order Euler scheme. The viscosity of the numerical scheme is negligible with respect to the fluid viscosity. The second-order upwind approximations of fluxes are based on the implicitly treated modified Leonard's QUICK approximations and the Total Variation Diminishing method [20,21]. The problem of pressure-velocity coupling is resolved with a SIMPLE-like approach. Fully implicit discrete convection-diffusion equations are solved to obtain flow parameters. To solve asymmetric systems of linear equations that arise from approximations of governing equations, a preconditioned generalized conjugate gradient method is used [22]. A double-preconditioned iterative procedure is used to solve algebraic equations of pressure-correction based on multi-grid method [23] Incomplete LU factorization is used for preconditioning. Preconditioning method is used to overcome the stiffness problem of the convective-flux Jacobian matrix. The preconditioning method is usually used to solve the cavitating flows because the cavitating flows can include all flow regimes of incompressible, subsonic, and supersonic speeds simultaneously [24]. Each CFD simulation generates a sample data. During shape optimization, the least square approximation of sample data yields a smooth curve. Then, the Newton's method is employed to approximate the optimum value. The degree of the least-square approximation was set to three.

\section{The numerical results}

\subsection{Geometrical characteristics}

Basic profile shapes for duct design are summarized in Figure 2. For all models, the inlet diameter is $0.50 \mathrm{~m}$ and throat diameter is $0.25 \mathrm{~m}$. Model $1-\mathrm{A}$ has a relatively thick profile with convex curvature in middle chord as well as inner and outer walls. It has a large angle of attack with outlet diameter of $0.56 \mathrm{~m}$. Model 1-B has smoother curvature at the outer wall than Model 1-A. It has outlet diameter of $0.72 \mathrm{~m}$. Model 1-C has small outlet diameter of $0.56 \mathrm{~m}$ but its thickness distribution increases in comparison with Model 1-B. Model 2-A has a large head shape. It has concave outer wall and convex inner wall. It has thin horizontal trailing edge with outlet diameter of $0.75 \mathrm{~m}$. Model 2-B is similar to Model 2-A but has smaller outlet diameter of $0.60 \mathrm{~m}$ and smaller inner wall curvature. In comparison to Models 2-A and 2B, Model 2-C has more straight inner wall with outlet diameter of $0.75 \mathrm{~m}$. Model 3-A has large head, thick profile, and step shaped trailing edge. It has outlet diameter of $0.25 \mathrm{~m}$. Model 3-B with large head, thick profile has concave curvature at inner and outer walls. It has outlet diameter of $0.25 \mathrm{~m}$. Model $3-\mathrm{C}$ with large head and thick profile has convex curvature at inner and outer walls. It has shorter length of $1.65 \mathrm{~m}$ and outlet diameter of $1.0 \mathrm{~m}$. Model $4-\mathrm{A}$ has a thin profile,

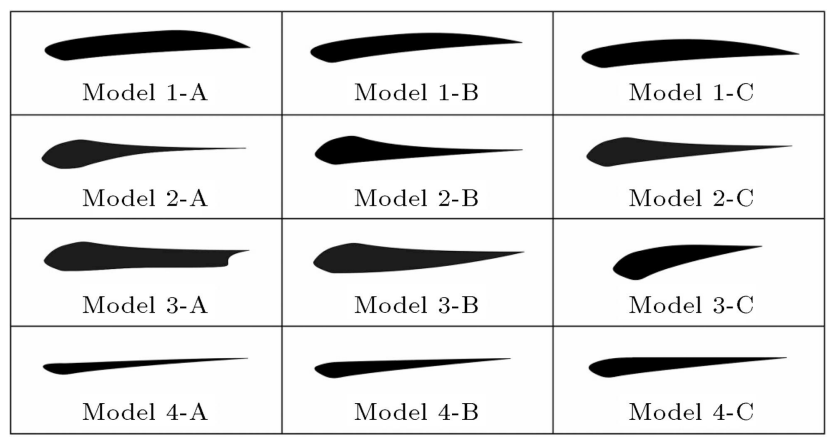

Figure 2. Basic profile shapes for duct design. 
nearly straight outer wall. It has outlet diameter of $0.75 \mathrm{~m}$. Model 4-B has thicker profile than Model 4A. It has convex curvature at inner wall, while having straight outer wall with a very low slope. The outlet diameter of Model 4-B is $0.75 \mathrm{~m}$. The outlet diameter for Model $4-\mathrm{C}$ is $0.75 \mathrm{~m}$. It has approximately thin profile, convex curvature at inner wall, and horizontal outer wall. Important data extracted from numerical simulations have been presented in Table 1. The drag force coefficient is based on the duct throat area $A=$ $0.049 \mathrm{~m}^{2}$, free stream velocity $u_{\infty}=3.0 \mathrm{~m} / \mathrm{sec}$, and fluid density $\rho=998 \mathrm{~kg} / \mathrm{m}^{3}$. While Models 2-A to $3-\mathrm{C}$ exhibit high throat velocity, numerical simulation in a complete three-dimensional domain exhibits unstable separated flow that rotates on duct walls. Models 2-A to 3-C have shown unsteady wake flow with oscillating mass flow rate at duct throat. In view of flow stability of the duct shapes summarized in Table 1, Model 4$\mathrm{C}$ can better hold a stable flow with reasonable high throat velocity while Model 3-B yields the highest kinetic energy flux at duct throat.

Velocity magnitude distribution along the duct axis for Models 1-A to 2-C is shown in Figure 3. Models 2-C and 2-A have greater values of area-averaged

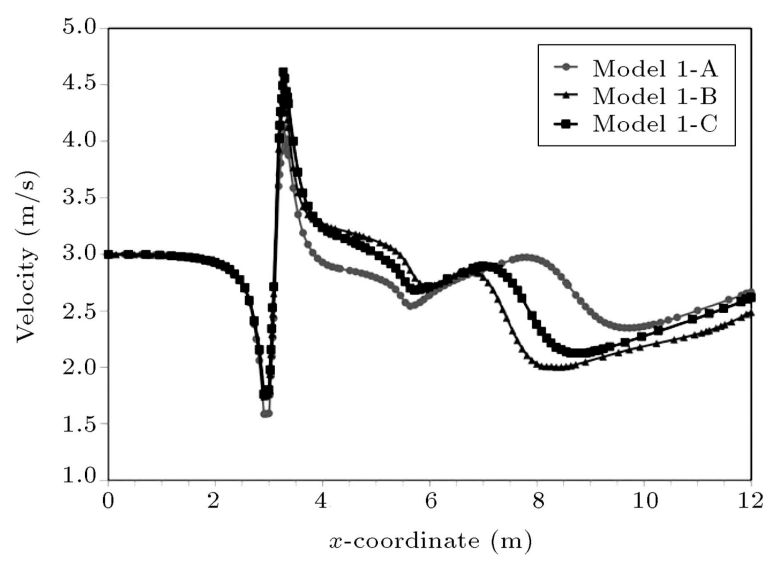

(a)

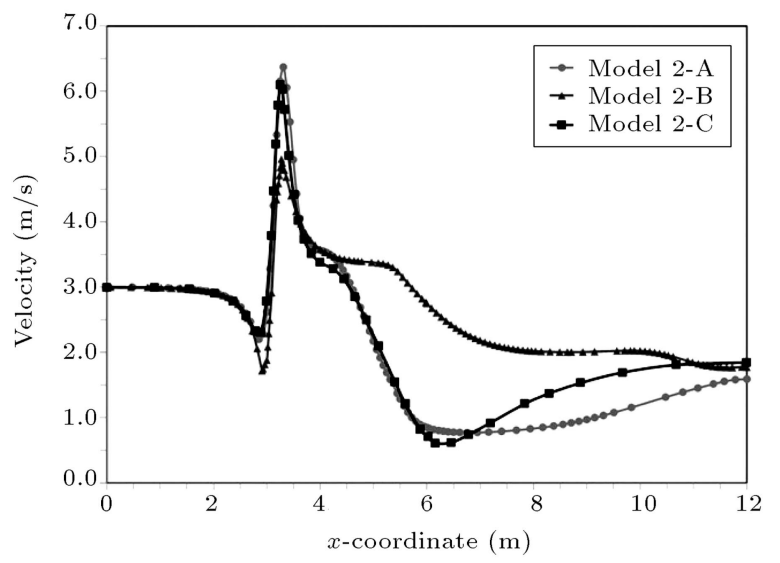

(b)

Figure 3. Distribution curves for velocity magnitude along the duct axis for Models 1-A to 2-C. velocity at duct throat. Models 1-A, 1-B, 1-C, and 2-B cannot sufficiently increase flow velocity at duct throat.

Velocity magnitude distribution along the duct axis for Models 3-A to $4-\mathrm{C}$ is shown in Figure 4. The maximum area-averaged velocity magnitude at duct throat is $6.70 \mathrm{~m} / \mathrm{sec}$ that belongs to Model 3B. Referring to Figures 3 and 4 , the area-averaged throat velocities for Models 2-A, 2-C, and 3-A are also great values of $6.31 \mathrm{~m} / \mathrm{sec}, 6.43 \mathrm{~m} / \mathrm{sec}$, and $6.47 \mathrm{~m} / \mathrm{sec}$, respectively. Models 2-A, 2-C, and 3-A exhibit unsteady oscillation when they are simulated in a full three-dimensional domain. Models 2-A, 2$\mathrm{C}$, and 3-A cannot satisfy flow stability. Model 3-C cannot sufficiently increase flow velocity at duct throat as a result of highly separated flow. Although the areaaveraged throat velocities for Models 4-A and 4-B are higher than that for Model 4-C, the flow stability of Model 4-C is higher. Boundary layer separation is more apparent in the flow around Models 4-A and 4-B.

Various configurations of duct for head, thickness, curvature, leading edge, and trailing edge are summarized in Figure 5. Model 5- $\mathrm{A}$ is the same as Model 4-C. It is a base shape with reasonable high throat velocity

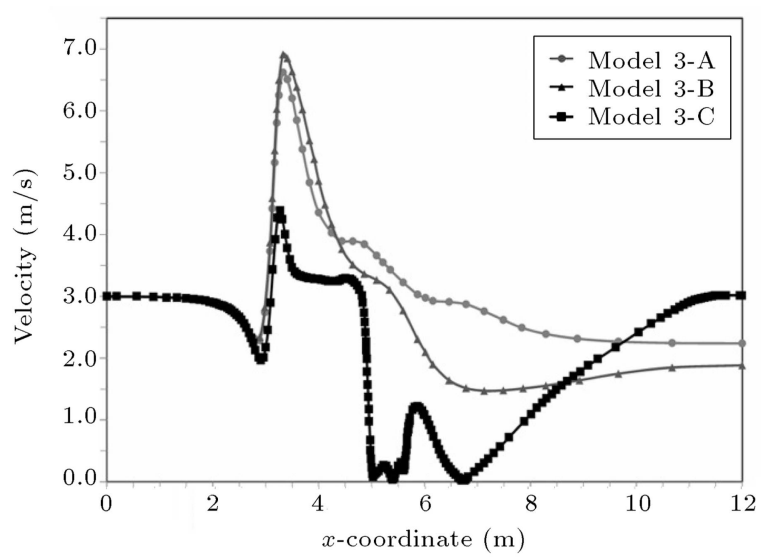

(a)

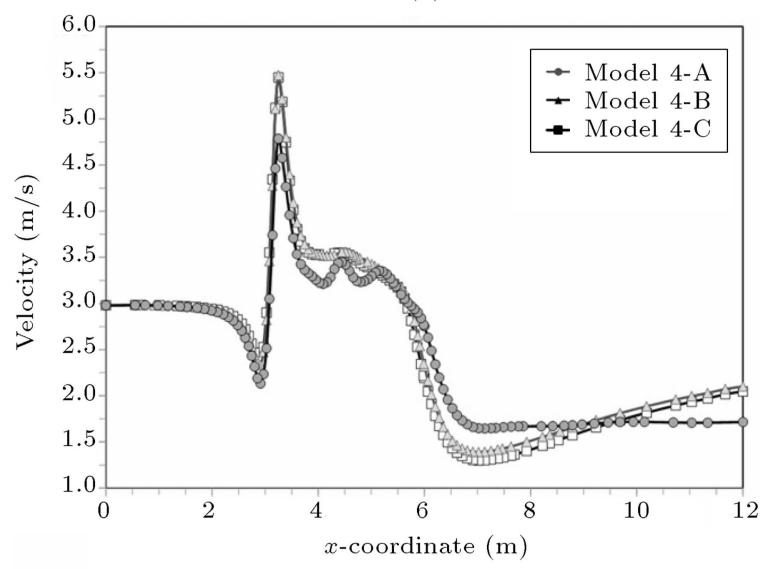

(b)

Figure 4. Distribution curves for velocity magnitude along the duct axis for Models 3-A to 4-C. 
Table 1. Numerical simulation results for Models 1-A to 4-C.

\begin{tabular}{|c|c|c|c|c|}
\hline Model & $\begin{array}{c}\text { Center-line } \\
\text { velocity }(\mathrm{m} / \mathrm{sec}) \\
\& \text { pressure }(\mathrm{Pa})\end{array}$ & $\begin{array}{l}\text { Drag } \\
\text { force } \\
(\mathrm{kN})\end{array}$ & $\begin{array}{c}\text { Drag } \\
\text { coefficient }\end{array}$ & $\begin{array}{l}\text { Throat } \\
\text { velocity } \\
(\mathrm{m} / \mathrm{sec})\end{array}$ \\
\hline \multirow{3}{*}{$1-\mathrm{A}$} & $u_{\max }=4.12$ & $F_{p}=1.64$ & $C_{D, P}=1.87$ & $u_{\max , \mathrm{th}}=3.78$ \\
\hline & $P_{\max }=3137$ & $F_{f}=0.35$ & $C_{D, f}=0.40$ & $u_{\min , \mathrm{th}}=3.23$ \\
\hline & $P_{\min }=-3131$ & $F_{\text {tot }}=1.99$ & $C_{D}=2.26$ & $u_{\text {ave }, \mathrm{th}}=3.56$ \\
\hline \multirow{3}{*}{$1-B$} & $u_{\max }=4.47$ & $F_{p}=2.42$ & $C_{D, P}=2.76$ & $u_{\max , \mathrm{th}}=4.33$ \\
\hline & $P_{\max }=2797$ & $F_{f}=0.35$ & $C_{D, f}=0.40$ & $u_{\min , \mathrm{th}}=3.47$ \\
\hline & $P_{\min }=-4417$ & $F_{\text {tot }}=2.77$ & $C_{D}=3.16$ & $u_{\mathrm{ave}, \mathrm{th}}=3.91$ \\
\hline \multirow{3}{*}{$1-\mathrm{C}$} & $u_{\max }=4.61$ & $F_{p}=1.88$ & $C_{D, P}=2.14$ & $u_{\max , \mathrm{th}}=4.46$ \\
\hline & $P_{\max }=2724$ & $F_{f}=0.37$ & $C_{D, f}=0.42$ & $u_{\min , \mathrm{th}}=3.65$ \\
\hline & $P_{\min }=-4954$ & $F_{\text {tot }}=2.25$ & $C_{D}=2.56$ & $u_{\text {ave }, \text { th }}=4.07$ \\
\hline \multirow{3}{*}{$2-\mathrm{A}$} & $u_{\max }=6.37$ & $F_{p}=2.23$ & $C_{D, P}=2.54$ & $u_{\max , \mathrm{th}}=6.74$ \\
\hline & $P_{\max }=2002$ & $F_{f}=0.25$ & $C_{D, f}=0.28$ & $u_{\min , \mathrm{th}}=6.16$ \\
\hline & $P_{\min }=-15383$ & $F_{\text {tot }}=2.48$ & $C_{D}=2.82$ & $u_{\text {ave }, \text { th }}=6.31$ \\
\hline \multirow{3}{*}{$2-\mathrm{B}$} & $u_{\max }=4.96$ & $F_{p}=2.55$ & $C_{D, P}=2.9$ & $u_{\max , \mathrm{th}}=4.80$ \\
\hline & $P_{\max }=2753$ & $F_{f}=0.27$ & $C_{D, f}=0.31$ & $u_{\min , \mathrm{th}}=4.04$ \\
\hline & $P_{\min }=-6415$ & $F_{\text {tot }}=2.82$ & $C_{D}=3.21$ & $u_{\text {ave }, \text { th }}=4.39$ \\
\hline \multirow{3}{*}{$2-\mathrm{C}$} & $u_{\max }=6.10$ & $F_{p}=2.23$ & $C_{D, P}=2.54$ & $u_{\max , \mathrm{th}}=6.87$ \\
\hline & $P_{\max }=1733$ & $F_{f}=0.23$ & $C_{D, f}=0.26$ & $u_{\min , \mathrm{th}}=6.05$ \\
\hline & $P_{\min }=-13635$ & $F_{\text {tot }}=2.46$ & $C_{D}=2.80$ & $u_{\text {ave }, \text { th }}=6.43$ \\
\hline \multirow{3}{*}{$3-\mathrm{A}$} & $u_{\max }=6.62$ & $F_{p}=1.63$ & $C_{D, P}=1.85$ & $u_{\max , \mathrm{th}}=6.91$ \\
\hline & $P_{\max }=1723$ & $F_{f}=0.31$ & $C_{D, f}=0.36$ & $u_{\min , \mathrm{th}}=6.25$ \\
\hline & $P_{\min }=-16476$ & $F_{\text {tot }}=1.94$ & $C_{D}=2.21$ & $u_{\text {ave }, \text { th }}=6.47$ \\
\hline \multirow{3}{*}{$3-\mathrm{B}$} & $u_{\max }=6.91$ & $F_{p}=2.11$ & $C_{D, P}=2.40$ & $u_{\max , \mathrm{th}}=7.14$ \\
\hline & $P_{\max }=1650$ & $F_{f}=0.30$ & $C_{D, f}=0.33$ & $u_{\min , \mathrm{th}}=6.50$ \\
\hline & $P_{\min }=-18614$ & $F_{\text {tot }}=2.41$ & $C_{D}=2.73$ & $u_{\text {ave }, \text { th }}=6.70$ \\
\hline \multirow{3}{*}{$3-\mathrm{C}$} & $u_{\max }=4.38$ & $F_{p}=3.75$ & $C_{D, P}=4.27$ & $u_{\max , \mathrm{th}}=4.77$ \\
\hline & $P_{\max }=2593$ & $F_{f}=0.27$ & $C_{D, f}=0.31$ & $u_{\min , \mathrm{th}}=4.31$ \\
\hline & $P_{\min }=-4949$ & $F_{\text {tot }}=4.02$ & $C_{D}=4.57$ & $u_{\text {ave }, \mathrm{th}}=4.61$ \\
\hline \multirow{3}{*}{$4-\mathrm{A}$} & $u_{\max }=5.45$ & $F_{p}=2.83$ & $C_{D, P}=3.22$ & $u_{\max , \mathrm{th}}=5.98$ \\
\hline & $P_{\max }=1586$ & $F_{f}=0.17$ & $C_{D, f}=0.20$ & $u_{\min , \mathrm{th}}=5.45$ \\
\hline & $P_{\min }=-9673$ & $F_{\text {tot }}=3.00$ & $C_{D}=3.42$ & $u_{\text {ave }, \text { th }}=5.65$ \\
\hline \multirow{3}{*}{$4-B$} & $u_{\max }=5.47$ & $F_{p}=2.71$ & $C_{D, P}=3.08$ & $u_{\max , \mathrm{th}}=6.03$ \\
\hline & $P_{\max }=1673$ & $F_{f}=0.21$ & $C_{D, f}=0.24$ & $u_{\min , \mathrm{th}}=5.47$ \\
\hline & $P_{\min }=-9733$ & $F_{\text {tot }}=2.92$ & $C_{D}=3.32$ & $u_{\text {ave }, \text { th }}=5.69$ \\
\hline \multirow{3}{*}{$4-\mathrm{C}$} & $u_{\max }=4.88$ & $F_{p}=2.17$ & $C_{D, P}=2.47$ & $u_{\max , \mathrm{th}}=5.37$ \\
\hline & $P_{\max }=2062$ & $F_{f}=0.22$ & $C_{D, f}=0.26$ & $u_{\min , \mathrm{th}}=4.88$ \\
\hline & $P_{\min }=-6883$ & $F_{\text {tot }}=2.39$ & $C_{D}=2.73$ & $u_{\text {ave }, \mathrm{th}}=5.06$ \\
\hline
\end{tabular}


Table 2. Numerical simulation results for Models 5-A to 7-C.

\begin{tabular}{|c|c|c|c|c|}
\hline Model & $\begin{array}{c}\text { Center-line } \\
\text { velocity }(\mathrm{m} / \mathrm{sec}) \\
\& \text { pressure }(\mathrm{Pa})\end{array}$ & $\begin{array}{l}\text { Drag } \\
\text { force } \\
(\mathrm{kN})\end{array}$ & $\begin{array}{c}\text { Drag } \\
\text { coefficient }\end{array}$ & $\begin{array}{l}\text { Throat } \\
\text { velocity } \\
(\mathrm{m} / \mathrm{sec})\end{array}$ \\
\hline $5-\mathrm{A}$ & $\begin{array}{l}u_{\max }=4.88 \\
P_{\max }=2062 \\
P_{\min }=-6883\end{array}$ & $\begin{array}{l}F_{p}=2.17 \\
F_{f}=0.22 \\
F_{\text {tot }}=2.39\end{array}$ & $\begin{array}{l}C_{D, P}=2.47 \\
C_{D, f}=0.26 \\
C_{D}=2.73\end{array}$ & $\begin{array}{l}u_{\max , \mathrm{th}}=5.37 \\
u_{\min , \mathrm{th}}=4.88 \\
u_{\text {ave,th }}=5.06\end{array}$ \\
\hline $5-\mathrm{B}$ & $\begin{array}{l}u_{\max }=4.12 \\
P_{\max }=2267 \\
P_{\min }=-3284\end{array}$ & $\begin{array}{l}F_{p}=1.35 \\
F_{f}=0.20 \\
F_{\text {tot }}=1.55\end{array}$ & $\begin{array}{l}C_{D, P}=1.53 \\
C_{D, f}=0.23 \\
C_{D}=1.76\end{array}$ & $\begin{array}{l}u_{\max , \mathrm{th}}=4.21 \\
u_{\min , \mathrm{th}}=2.95 \\
u_{\text {ave } \mathrm{th}}=3.83\end{array}$ \\
\hline $5-\mathrm{C}$ & $\begin{array}{l}u_{\max }=4.71 \\
P_{\max }=2718 \\
P_{\min }=-5687\end{array}$ & $\begin{array}{l}F_{p}=4.39 \\
F_{f}=0.17 \\
F_{\text {tot }}=4.56\end{array}$ & $\begin{array}{l}C_{D, P}=4.99 \\
C_{D, f}=0.19 \\
C_{D}=5.18\end{array}$ & $\begin{array}{l}u_{\max , \text { th }}=4.54 \\
u_{\min , \mathrm{th}}=3.79 \\
u_{\text {ave,th }}=4.17\end{array}$ \\
\hline $6-\mathrm{A}$ & $\begin{array}{l}u_{\max }=6.06 \\
P_{\max }=1501 \\
P_{\min }=-12351\end{array}$ & $\begin{array}{l}F_{p}=2.74 \\
F_{f}=0.29 \\
F_{\text {tot }}=3.03\end{array}$ & $\begin{array}{l}C_{D, P}=3.12 \\
C_{D, f}=0.33 \\
C_{D}=3.45\end{array}$ & $\begin{array}{l}u_{\max , \mathrm{th}}=5.95 \\
u_{\min , \mathrm{th}}=5.28 \\
u_{\text {ave,th }}=5.75\end{array}$ \\
\hline $6-\mathrm{B}$ & $\begin{array}{l}u_{\max }=6.26 \\
P_{\max }=1533 \\
P_{\min }=-14279\end{array}$ & $\begin{array}{l}F_{p}=1.80 \\
F_{f}=0.33 \\
F_{\text {tot }}=2.13\end{array}$ & $\begin{array}{l}C_{D, P}=2.06 \\
C_{D, f}=0.37 \\
C_{D}=2.43\end{array}$ & $\begin{array}{l}u_{\max , \text { th }}=5.89 \\
u_{\min , \text { th }}=5.36 \\
u_{\text {ave } \text { th }}=5.71\end{array}$ \\
\hline $6-\mathrm{C}$ & $\begin{array}{l}u_{\max }=6.18 \\
P_{\max }=1671 \\
P_{\min }=-14168\end{array}$ & $\begin{array}{l}F_{p}=1.77 \\
F_{f}=0.36 \\
F_{\text {tot }}=2.13\end{array}$ & $\begin{array}{l}C_{D, P}=2.01 \\
C_{D, f}=0.41 \\
C_{D}=2.42\end{array}$ & $\begin{array}{l}u_{\max , \mathrm{th}}=5.53 \\
u_{\min , \mathrm{th}}=5.13 \\
u_{\text {ave } \mathrm{th}}=5.42\end{array}$ \\
\hline $7-\mathrm{A}$ & $\begin{array}{l}u_{\max }=5.88 \\
P_{\max }=1601 \\
P_{\min }=-11336\end{array}$ & $\begin{array}{l}F_{p}=1.81 \\
F_{f}=0.31 \\
F_{\text {tot }}=2.12\end{array}$ & $\begin{array}{l}C_{D, P}=2.06 \\
C_{D, f}=0.35 \\
C_{D}=2.41\end{array}$ & $\begin{array}{l}u_{\max , \mathrm{th}}=5.66 \\
u_{\min , \mathrm{th}}=5.06 \\
u_{\text {ave }, \mathrm{th}}=5.50\end{array}$ \\
\hline $7-B$ & $\begin{array}{l}u_{\max }=5.26 \\
P_{\max }=1948 \\
P_{\min }=-8257\end{array}$ & $\begin{array}{l}F_{p}=1.74 \\
F_{f}=0.27 \\
F_{\text {tot }}=2.01\end{array}$ & $\begin{array}{l}C_{D, P}=1.98 \\
C_{D, f}=0.31 \\
C_{D}=2.28\end{array}$ & $\begin{array}{l}u_{\max , \mathrm{th}}=5.05 \\
u_{\min , \mathrm{th}}=4.52 \\
u_{\text {ave }, \mathrm{th}}=4.91\end{array}$ \\
\hline $7-\mathrm{C}$ & $\begin{array}{l}u_{\max }=6.31 \\
P_{\max }=1543 \\
P_{\min }=-14923\end{array}$ & $\begin{array}{l}F_{p}=2.05 \\
F_{f}=0.38 \\
F_{\text {tot }}=2.43\end{array}$ & $\begin{array}{l}C_{D, P}=2.33 \\
C_{D, f}=0.44 \\
C_{D}=2.77\end{array}$ & $\begin{array}{l}u_{\max , \mathrm{th}}=5.86 \\
u_{\min , \mathrm{th}}=5.43 \\
u_{\text {ave,th }}=5.73\end{array}$ \\
\hline
\end{tabular}

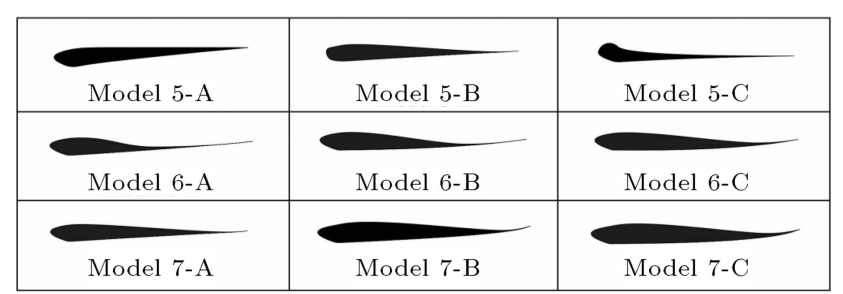

Figure 5. Various configurations of duct for head, thickness, curvature, leading edge, and trailing edge.

and can be modified according to Figure 5 to increase throat velocity while holding the flow stability. Model 5-B has a flat shaped head, convex curvature at outer wall, and thin rolled trailing edge. The outlet diameter of Model 5-B is $0.52 \mathrm{~m}$. Model 5-C has a bumpy shaped head, concave curvature at the outer wall, and straight thin trailing edge. It has outlet diameter of $0.41 \mathrm{~m}$.

Important modifications for the shape of duct models that have been summarized in Figure 2 are inserted in Model 6-A. It has convex-concave curvature at outer wall with straight trailing edge. Model 6-A has outlet diameter of $0.60 \mathrm{~m}$. Models 6 -B to $7-\mathrm{C}$ are modified shapes with a head similar to Model 6A. These models have thin rolled trailing edges. The outlet diameter of Models 6-B, 6-C, and 7-A is $0.52 \mathrm{~m}$. The outlet diameters for Models $7-\mathrm{B}$ and 7 -C are 0.65 $\mathrm{m}$ and $0.60 \mathrm{~m}$, respectively. Numerical simulation data for Models 5-A to 7-C have been summarized in Table 2. Among the duct models shown in Tables 1 and 2, Model 5-C has the greatest total drag coefficient, 
$C_{D}=5.18$, and the greatest pressure drag coefficient, $C_{D, P}=4.99$. The bumpy shaped head of Model 5-C increases the drag coefficient. The smallest frictional drag coefficient is $C_{D, f}=0.19$, belonging to Model 5$\mathrm{C}$ for which the boundary layer is strongly separated at outer side of the duct. The smallest total drag coefficient, $C_{D}=1.76$, and the smallest pressure drag coefficient, $C_{D, P}=1.53$, are of Model 5 -B. Model 5 -B has the smallest exit area of $0.21 \mathrm{~m}^{2}$ that is caused to gain the least total drag coefficient. Among various duct models shown in Figure 5, the greatest values of pressure increase before duct entrance are $1.50 \mathrm{kPa}, 1.53 \mathrm{kPa}, 1.54 \mathrm{kPa}$, and $1.60 \mathrm{kPa}$ for Models 6-A, 6-B, 7-C, and 7-A, respectively. Distribution curves for velocity magnitude and relative pressure along the duct axis for Models 5-A to 6- $\mathrm{C}$ are shown in Figure 6. In the wake region between $x=6.5 \mathrm{~m}$ to $x=12.0 \mathrm{~m}$ on the duct axis, the flow pressure has reached the free-stream pressure. However, the velocity magnitude curves shown in Figure 6 slightly deviate in the wake region. Model 5-B with the minimum exit area and bumpy shaped head produces the most flow blockage. It maintains the central wake velocity in higher values than the free stream velocity.

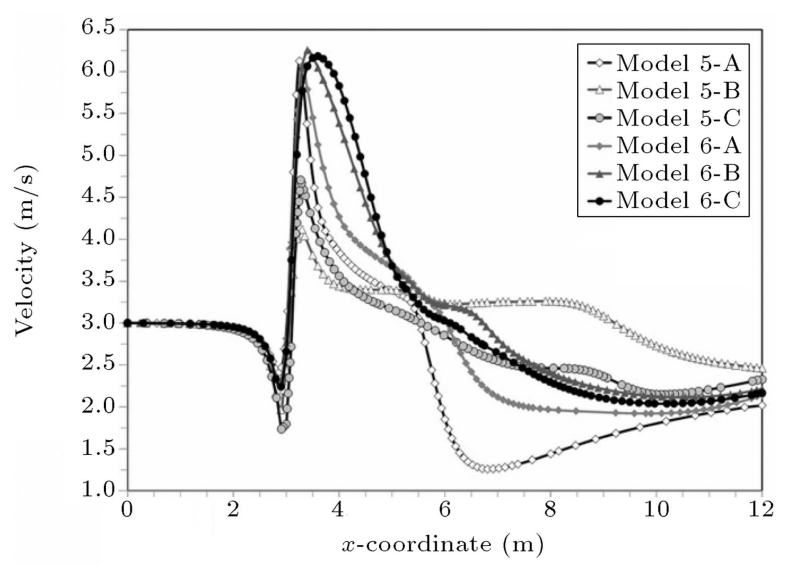

(a)

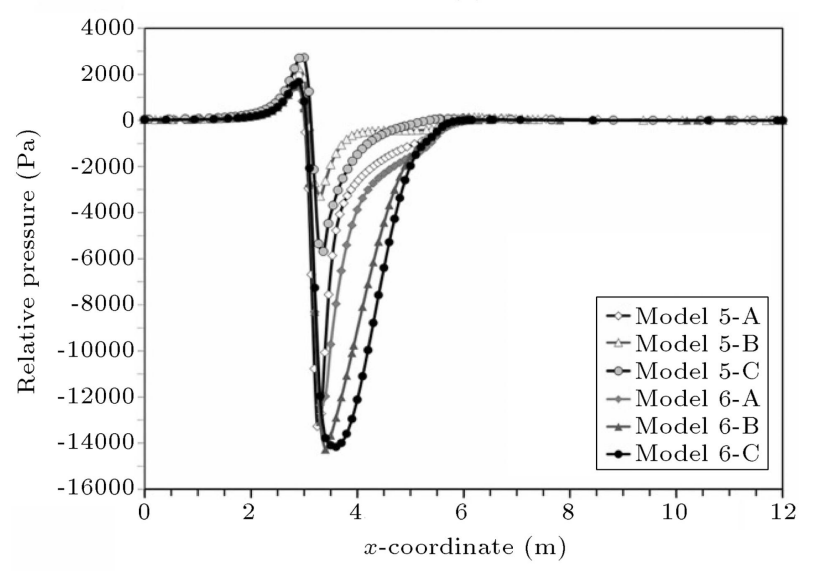

(b)

Figure 6. Distribution curves for velocity magnitude and pressure along the duct axis for Models 5-A to 6-C.

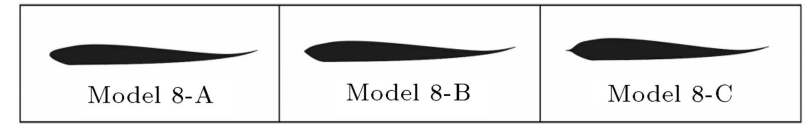

Figure 7. Leading edge optimization for profile shape of Model 7-C.

Figure 6 well describes the wake recovery for various duct shapes.

According to Figure 7, three shapes for leading edge of the duct profile were considered. Models 8-A to 8-C have the same profile shape, with outlet diameter of $0.60 \mathrm{~m}$, but have different leading edges. As illustrated in Figure 8, the throat velocity for Model 8-C is higher than that for Models 8-A and 8-B. With needle shaped leading edge of Model 8-C, the throat velocity reaches $6.28 \mathrm{~m} / \mathrm{sec}$. With round shaped leading edge of Model 8 -A, the throat velocity is $5.86 \mathrm{~m} / \mathrm{sec}$. The throat velocity for Model 8-B with a sharp angled leading edge is $5.11 \mathrm{~m} / \mathrm{sec}$, which is the lowest value.

According to velocity curves shown in Figure 8, the leading edge shape has significant influence on the wake region and the throat velocity. For Model 8-A, the velocity decay in the wake starts rapidly after passing the duct. The minimum velocity in the

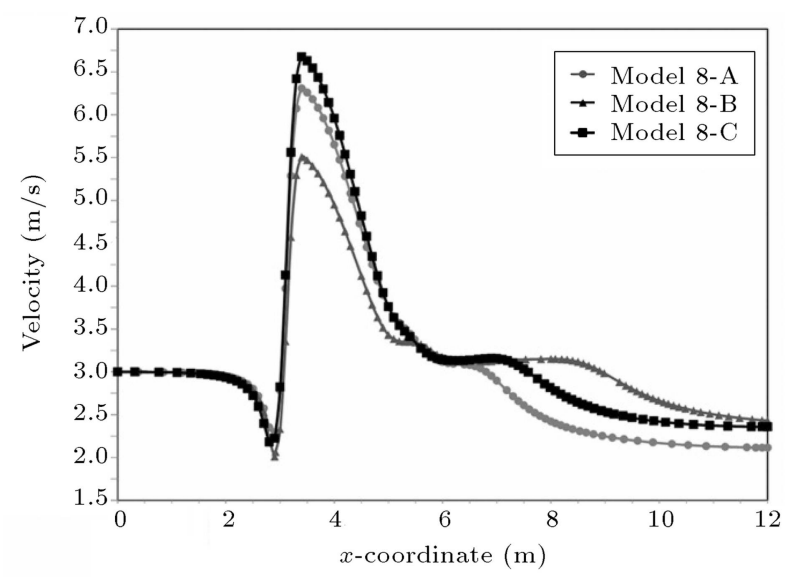

(a)

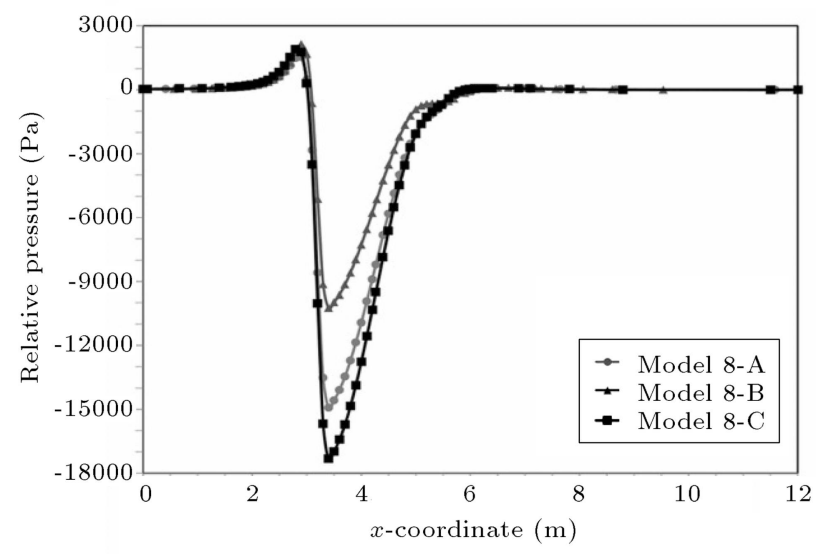

(b)

Figure 8. Distribution curves for velocity magnitude and pressure along the duct axis for Models 8-A to 8-C. 
Table 3. Numerical simulation results for Models 8-A to 8-C.

\begin{tabular}{|c|c|c|c|c|}
\hline Model & $\begin{array}{c}\text { Center-line } \\
\text { velocity }(\mathrm{m} / \mathrm{sec}) \\
\& \text { pressure }(\mathrm{Pa})\end{array}$ & $\begin{array}{l}\text { Drag } \\
\text { force } \\
(\mathrm{kN}) \\
\end{array}$ & $\begin{array}{c}\text { Drag } \\
\text { coefficient }\end{array}$ & $\begin{array}{c}\text { Throat } \\
\text { velocity } \\
(\mathrm{m} / \mathrm{sec})\end{array}$ \\
\hline \multirow{3}{*}{$8-\mathrm{A}$} & $u_{\max }=6.31$ & $F_{p}=2.05$ & $C_{D, P}=2.33$ & $u_{\max , \mathrm{th}}=5.86$ \\
\hline & $P_{\max }=1543$ & $F_{f}=0.38$ & $C_{D, f}=0.44$ & $u_{\min , \mathrm{th}}=5.43$ \\
\hline & $P_{\min }=-14923$ & $F_{\text {tot }}=2.43$ & $C_{D}=2.77$ & $u_{\text {ave }, \mathrm{th}}=5.73$ \\
\hline \multirow{3}{*}{$8-B$} & $u_{\max }=5.51$ & $F_{p}=1.62$ & $C_{D, P}=1.84$ & $u_{\max , \mathrm{th}}=5.11$ \\
\hline & $P_{\max }=2149$ & $F_{f}=0.30$ & $C_{D, f}=0.35$ & $u_{\min , \mathrm{th}}=4.64$ \\
\hline & $P_{\min }=-10240$ & $F_{\text {tot }}=1.92$ & $C_{D}=2.19$ & $u_{\text {ave }, \mathrm{th}}=4.96$ \\
\hline \multirow{3}{*}{$8-\mathrm{C}$} & $u_{\max }=6.68$ & $F_{p}=1.77$ & $C_{D, P}=2.02$ & $u_{\max , \mathrm{th}}=6.28$ \\
\hline & $P_{\max }=1910$ & $F_{f}=0.39$ & $C_{D, f}=0.45$ & $u_{\min , \mathrm{th}}=5.96$ \\
\hline & $P_{\min }=-17339$ & $F_{\text {tot }}=2.16$ & $C_{D}=2.46$ & $u_{\text {ave }, \mathrm{th}}=6.14$ \\
\hline
\end{tabular}

wake region is lowest for Model 8-A. This illustrates that a round shaped leading edge produces stronger wake downstream of the duct. The pressure curves in Figure 8 illustrate the effect of leading edge shape on throat pressure. Numerical simulation results for Models 8-A to 8-C are summarized in Table 3.

\subsection{Turbulence characteristics of the flow field}

Turbulence intensity is inversely proportional to eddy size. The turbulence intensity contours shown in Figure 9 illustrate locations around Models 3-C, 3$\mathrm{B}$, and $8-\mathrm{C}$, where small eddies with high fluctuation velocity are produced. Among all investigated duct shapes, Models 3-C, 3-B, and 8-C were compared for illustrating dependency of turbulence intensity on axial variation of flow passage area at the divergent section of ducts. While Models 3-C, 3-B, and 8$\mathrm{C}$ have similar head shapes and nearly the same thickness profile (in normalized axial coordinate at the divergent section), the mean-line profiles are obviously different in curvature. As shown in Figure 9, turbulent fluctuations in the flow around Model 3-C become moderate for Model 3-B and partially appear in the flow field around Model 8-C. For Model 3$\mathrm{C}$, the diverged section of the duct has very large slope that brings on flow separation just after the throat. Turbulent eddies are generated and developed downstream of the flow. A turbulent wake with high fluctuation is formed. For the diverged section of Model 3-C, the concave curvature of the inner duct wall produces a favorable pressure gradient against the adverse pressure gradient generated due to area changes. For this reason, eddies are damped near the concave wall. The streamlines passing through duct throat remain nearly parallel to the duct axis. This is the worst case for which the average throat velocity is 1.54 times the free stream velocity. In comparison to

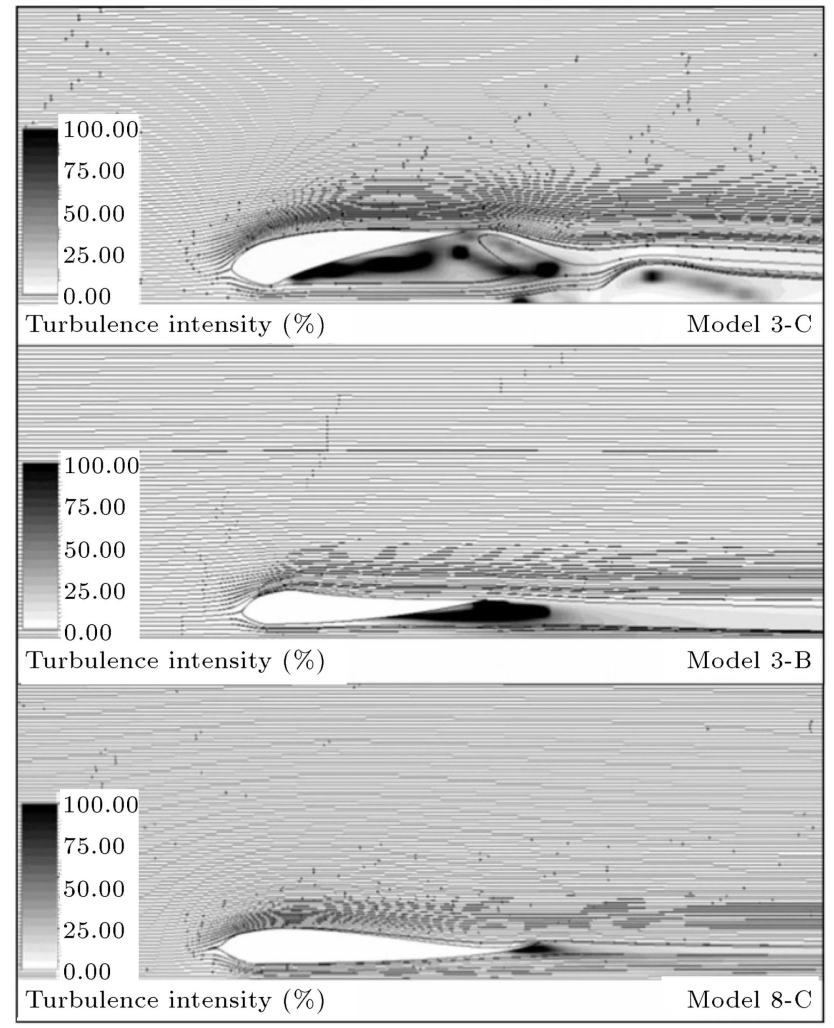

Figure 9. Reduction of turbulence intensity for duct Models 3-C, 3-B, and 8-C.

Model 3-C, the wall curvature at the diverged section of Model 3-B is inversed while Model 3-B has lower slope at the diverged section. Area change in the axial direction is the dominant parameter, which influences boundary layer separation and its location. For Model 3 -B, the turbulent intensity increases at the trailing edge. Smaller eddies are formed near the trailing edge. The wake turbulent characteristic is different than that for Model 3-C. Streamlines passing the throat expand to middle distance of diverged section; 
then, they interact with turbulent eddies with high fluctuating velocity. This makes the streamlines be contracted when inserted into the wake. Model 3$\mathrm{B}$ produces the highest averaged throat velocity in comparison with other models. However, it is still not the best design because the flow separation generates a large unstable turbulent area that would not exhibit circumferential symmetry in a full-domain simulation. In Models 3-B and 3-C, shear flow with turbulent mixing is observed where inner flow streamlines are separated from the outer flow streamlines or not matched smoothly. The turbulent mixing loss in the wake attenuates the duct performance. In Model 8-C, the trailing edge design delays flow separation and reduces turbulence area. Turbulent intensity contour plot for Model 8-C illustrates much less production of turbulent eddies than Models 3-B and 3C. Streamlines of Model 8-C continue to expand at the diverged section until they are inserted into the wake. Model $8-\mathrm{C}$ is a well diffuser augmented duct, because the inner and outer streamlines are matched after passing the duct. The needle shaped leading edge of Model 8-C helps the free stream flow to be divided inside and outside the duct. This can reduce static pressure at the duct entrance and the result is increase in throat velocity. With the same inlet area of $0.20 \mathrm{~m}^{2}$ and throat area of $0.049 \mathrm{~m}^{2}$, the exit areas of Models 3-C, 3-B, and 8-C are $0.786 \mathrm{~m}^{2}, 0.442 \mathrm{~m}^{2}$, and $0.283 \mathrm{~m}^{2}$, respectively. When the exit area of the duct is lowered, the flow separation is partially removed and the axisymmetric duct can better act as a diffuser.

\subsection{Comparison with experiments}

Experimentally measured drag forces for smooth and rough tubular frustum were reported in [25]. Results of similar experiments for tubular-truncated cones were reported in [26]. These data can be employed to validate the numerical solution method used for predictions of duct drag coefficient. True dimensions of the tubular cone are closely a scale of 0.1372 of the duct-Model 4-A. The experimented tubular cone can be investigated as a basic shape because it has the main geometrical characteristics and resembles various duct models. The cone angle is 5 degrees and its length is $0.343 \mathrm{~m}$. The cone wall has small thickness of $1 \mathrm{~mm}$ and the inlet and outlet diameters are $0.04 \mathrm{~m}$ and $0.10 \mathrm{~m}$, respectively. Experimentally measured drag forces cover a wide range of flow Reynolds numbers, $1.46 \times 10^{6}<\operatorname{Re}_{D}<5.53 \times 10^{6}$. The flow Reynolds number used in the numerical simulations is $\operatorname{Re}_{D}=2.25 \times 10^{6}$, which was computed based on the duct throat diameter. In the experiments of reference [26], the flow direction is parallel to the tubular cone axis and the smaller area is faced with the flow direction such that tubular cone acts as a diffuser. For a suitable comparison, the experimentally measured drag forces were non-dimensioned based on the frontal cross sectional area (smallest flow passage area). In this case, the drag coefficients for smooth and rough tubular cones (with mean roughness of $1.5 \mathrm{~mm}$ ) were 3.41 and 3.62 , respectively. These values were recalculated from data in $[25,26]$. The numerical prediction of drag coefficient for Model 4-A with smooth walls is 3.42 . Model 4-A has very thin profile and well resembles the experimented tubular cone. There is only $0.3 \%$ difference between numerical drag coefficients of Model 4-A and experiments. The average drag coefficient for all of the duct configurations which were investigated in the present paper is 2.99. The average of numerically predicted drag coefficients is $12 \%$ lower than experimental data of a smooth tubular cone. The designed shapes have averagely smaller drag coefficient than that of a tubular cone, because the flow separation was reduced and streamlines were better distributed around the profiles. The presented comparison could numerically verify the predicted drag forces. Furthermore, in the experiments of $[25,26]$, cavitation was not observed around the tubular cone as it did not appear in the numerical simulations.

\section{Conclusions}

In the present paper, conceptual duct shape design was performed. With this method, the designer can study various duct shapes with different heads, thicknesses, curvatures, leading edges, and trailing edges. After numerical simulation of various duct models, the following important results were obtained:

- The technique used in defining a wedge shaped fluid sub-domain provides nearly axisymmetric flow around the duct while preserving three-dimensional turbulent characteristics of the fluid flow;

- Based on numerical simulation of the flow field around various duct shapes, the maximum areaaveraged flow velocity at duct throat is $6.70 \mathrm{~m} / \mathrm{sec}$ for Model 3-B;

- Based on the numerical simulations, a duct with needle shaped leading edge can increase throat velocity. The area-averaged flow velocity at duct throat for optimum duct shape (Model 8-C) is $6.14 \mathrm{~m} / \mathrm{sec}$;

- Among the investigated duct shapes, Model 5-C has the greatest total drag coefficient, $C_{D}=5.18$, and the greatest pressure drag coefficient, $C_{D, P}=4.99$. The bumpy shaped head of Model 5-C increases the drag coefficient;

- The smallest frictional drag coefficient is $C_{D, f}=$ 0.19 for Model 5-C, for which the boundary layer is strongly separated at outer side of the duct; 
- The duct exit area has high influence on the drag coefficient. The smallest drag coefficient, $C_{D}=$ 1.76, belongs to Model 5-B with the smallest exit area of $0.21 \mathrm{~m}^{2}$;

- Model 5-B with the minimum exit area and bumpy shaped head produces the most flow blockage. It holds the central wake velocity in higher values than the free stream velocity. The flow blockage can slightly reduce the kinetic energy flux at duct throat;

- The shape of Model 8-C, which provides more stable flow with a reasonably high average velocity at duct throat, is introduced as the best design of duct. This shape encounters minimum flow separation and the greatest frictional drag coefficient, $C_{D, f}=0.45$;

- The predicted drag coefficients are in agreement with experimentally measured drag forces for smooth and rough tubular frustum. There is only $0.3 \%$ difference between numerical drag coefficients of Model 4-A and experiments;

- The conceptual duct shape design can help the designer to find the best duct shape relying on physical characteristics of the flow field. With the presented method, the Flow-Simulation Software is reliable for designing duct shape for a horizontalaxis hydrokinetic turbine.

\section{Nomenclature}

\section{Latin symbols}

$A \quad$ Area of the duct throat $\left(\mathrm{m}^{2}\right)$

$C_{D, f} \quad$ Viscous drag force coefficient

$C_{D, p} \quad$ Pressure drag force coefficient

$C_{D, \text { tot }} \quad$ Total drag force coefficient

$F_{f} \quad$ Frictional (viscous) drag force (N)

$F_{p} \quad$ Pressure drag force (N)

$F_{\text {tot }} \quad$ Total drag force $(\mathrm{N})$

$S_{\varepsilon} \quad$ Source term for turbulent dissipation rate $\left(\mathrm{N} / \mathrm{m}^{2} \cdot \mathrm{s}^{2}\right)$

$S_{\kappa} \quad$ Source term for turbulent kinetic energy $\left(\mathrm{N} / \mathrm{m}^{2} . \mathrm{s}\right)$

$H \quad$ Total enthalpy of the mixture $(\mathrm{J} / \mathrm{kg})$

$h \quad$ Enthalpy of the mixture components $(\mathrm{J} / \mathrm{kg})$

$I_{c} \quad$ Impulse factor $\left(\mathrm{kg}^{2} / \mathrm{m}^{4} \cdot \mathrm{s}^{2}\right)$

$i \quad$ Space Cartesian coordinate

j Space Cartesian coordinate

$l \quad$ Liquid phase

n Mixture component

$m \quad$ Mixture phase $p$

$p_{\text {abs }} \quad$ Absolute pressure $(\mathrm{Pa})$

$p_{\text {sat }} \quad$ Saturation pressure $(\mathrm{Pa})$

$S \quad$ Rate of production or consumption of mixture components

$u \quad$ The average velocity of the mixture phase $(\mathrm{m} / \mathrm{s})$

$u_{\text {ave,th }} \quad$ Average throat velocity $(\mathrm{m} / \mathrm{s})$

$u_{\infty} \quad$ Free stream velocity $(\mathrm{m} / \mathrm{s})$

$u_{\max } \quad$ Maximum center-line velocity $(\mathrm{m} / \mathrm{s})$

$u_{\text {max }, \text { th }} \quad$ Maximum throat velocity $(\mathrm{m} / \mathrm{s})$

$u_{\text {min,th }} \quad$ Minimum throat velocity $(\mathrm{m} / \mathrm{s})$

$P_{\max } \quad$ Maximum center-line pressure $(\mathrm{Pa})$

$P_{\min } \quad$ Minimum center-line pressure $(\mathrm{Pa})$

y Species concentration.

\section{Greek symbols}

$\begin{array}{ll}\delta_{i j} & \text { Kronecker delta } \\ \varepsilon & \text { Turbulent dissipation rate }\left(\mathrm{m}^{2} / \mathrm{s}^{3}\right) \\ \kappa & \text { Turbulent kinetic energy }\left(\mathrm{m}^{2} / \mathrm{s}^{2}\right) \\ \rho & \text { Density }\left(\mathrm{kg} / \mathrm{m}^{3}\right) \\ \rho_{m} \overline{u_{i}^{\prime} u_{j}^{\prime}} & \text { Reynolds stress components } \\ \sigma_{\varepsilon}=1.2 & \text { Constant of turbulence equations } \\ \sigma_{\kappa}=1.0 & \text { Constant of turbulence equations } \\ v & \text { Coefficient of kinematic viscosity } \\ & \left(\mathrm{m}^{2} / \mathrm{s}\right) .\end{array}$

\section{References}

1. Ginter, V. and Bear, C. "Development and application of a water current turbine", New Energy Corporation Inc., pp. 1-14 (2007).

2. Khan, M.J., Iqbal, M.T. and Quaicoe, J.E. "River current turbine technology: progress, prospects and challenges", 15th IEEE NECEC Conference, St. John's, Newfoundland, Canada, pp. 1-9 (2005).

3. Strickland, J.H., Webster, B.T. and Nguyen, T. "Vortex model of the Darrieus turbine: an analytical and experimental study", ASME, J. Fluids Eng., 101(4), pp. 500-505 (1979).

4. Wang, X., Luo, X., Zhuang, B., Yu, W. and Xu, H. "6DOF numerical simulation of the vertical-axis water turbine", ASME-JSME-KSME Joint Fluids Engineering Conference, 1, pp. 673-678 (2011).

5. McAdam, R. "Studies into the technical feasibility of the transverse horizontal axis water turbine", A Thesis Submitted for the Degree of Doctor of Philosophy, Oxford university (2011).

6. Kirke, B. "Development in ducted water current turbines", Tidal Paper., School of Engineering, Griffith University, Australia, pp. 1-12 (2003). 
7. Lawn, C.J. "Optimization of the power output from ducted turbines", Proc. Inst. Mech. Eng. A J. Power Energy, 217, pp. 107-117 (2003).

8. Wern, K., Lam, W.H. and Ching, K.C. "Review 20022012: 10 years research progress in horizontal-axis marine current turbines", Open Access Energies, 6, pp. 1497-1526 (2013).

9. Setoguchi, T., Shiomi, N. and Kaneko, K. "Development of two-way diffuser for fluid energy conversion system", Renew. Energy, 29, pp. 1757-1771 (2004).

10. Bryden, I.G. and Melville, G.T. "Choosing and evaluating sites for tidal current development", Proc. Inst. Mech. Eng. A J., Power Energy, 218, pp. 567-577 (2004).

11. Bryden, I.G., Grinsted, T. and Melville, G.T. "Assessing the potential of a simple tidal channel to deliver useful energy", Appl. Ocean Res., 26, pp. 198-204 (2004).

12. Garrett, C. and Cummins, P. "Generating power from tidal current", J. Waterw. Port. C-ASCE 2004, 130, pp. 114-118 (2004).

13. Garrett, C. and Cummins, P. "Limits to tidal current power", Renew. Energy, 33, pp. 2485-2490 (2008).

14. Munch, C., Vonlanthen, M., Gomes, J., Luquet, R., Guinard, P. and Avellan, F. "Design and Performance Assessment of A Tidal Ducted Turbine", In Proceedings of the 3rd IAHR International Meeting of the Workgroup on Cavitation and Dynamic Problems in Hydraulic Machinery and Systems, Brno, Czech Republic, pp. 571-581 (2009).

15. Shives, M. and Crawford, C. "Overall efficiency of ducted tidal current turbines", In Proceedings of the Oceans, Seattle, WA, USA, pp. 1-6 (2010).

16. Shives, M. and Crawford, C. "Developing an empirical model for ducted tidal turbine performance using numerical simulation results", Proc. Inst. Mech. Eng. A J. Power Energy, 226, pp. 112-125 (2012).

17. Todd, T.A.O., Favre-Averaged Navier-Stokes and Turbulence Model Equation Documentation, Technical Paper, Institute for Computational Engineering and Sciences, The University of Texas, Austin (2009).

18. "SolidWorks flow simulation 2013 technical reference", Dassault Systems, SolidWorks Corporation, USA, pp. 3-14 (2013).

19. Ladokun, L.L., Ajao, K.R. and Sule, B.F. "Hydrokinetic energy conversion systems: prospects and challenges in Nigerian hydrological setting", Nigerian Journal of Technology, 32(3), pp. 538-549 (2013).

20. Roache, P.J., Technical Reference of Computational Fluid Dynamics, Hermosa publishers, Albuquerque, New Mexico, USA (1998).
21. Hirsch, C. "Numerical computation of internal and external flows", Fundamentals of Computational Fluid Dynamics, 1, 2th Edn., pp. 366-398, John Wiley and Sons, Ltd (2007).

22. Saad, Y., Iterative Methods for Sparse Linear Systems, 1th Edn., pp. 196-360, PWS Publishing Company, Boston (1996).

23. Hackbusch, W., Multi-Grid Methods and Applications, 1th Edn., pp. 1-377, Springer-Verlag, Berlin, Heidelberg, New York, Tokyo (1985).

24. Kunz, R.F., Boger, D.A., Stinebring, D.R., Thomas, S.Ch., Jules, W.L., Gibeling, H.J., Venkateswaran, S. and Govindan, T.R. "A preconditioned NavierStokes method for two-phase flows with application to cavitation prediction", Computers and Fluids, 29(8), pp. 849-875 (2000).

25. Niknafs Abrebekooh, Y. and Rad, M. "Experimental and numerical investigation of drag force over tubular frustum", Scientia Iranica, 18(5), pp. 1133-1137 (2011).

26. Lotfi, A. and Rad, M. "Drag performance of divergent tubular-truncated cones: a shape optimization study", International Journal of Environmental Science and Technology, 9(1) (2011). DOI:10.1007/s13762-0110003-9

\section{Biographies}

Ali Zahedi Nejad is PhD student of Mechanical Engineering at Islamic Azad University of Science and Research Branch of Tehran, Iran. He has extensive research in the field of micro heat pipes and cavitation modeling. His major interests include energy conversion, heat and mass transfer, multiphase flows, and mathematical modeling of mechanical systems.

Manouchehr Rad is a retired Professor in the School of Mechanical Engineering at Sharif University of Technology and the Islamic Azad University of Tehran. He has $\mathrm{PhD}$ in Civil Engineering (Hydrodynamics) from the University of Imperial College of London. He has BSc and MSc in Mechanical Engineering from S.J.S.U of California and P.G.D.H.D Netherland, respectively. His research interests include drag reduction, cavitation, energy conversion, applied hydrodynamics, and aerodynamics.

Morteza Khayat obtained his PhD in Mechanical Engineering from Sharif University of Technology (SUT), Tehran, Iran. His major interest areas are multiphase flow, heat transfer in porous media, and non-Newtonian fluid flow. 